\section{Micropropagation of Pyracantha coccinea}

\author{
Chao Dong, Xue Li, and Yue Xi \\ College of Horticulture, Nanjing Agricultural University, 210095 Nanjing, \\ Jiang Su, China
}

\section{Zong-Ming Cheng ${ }^{1}$}

College of Horticulture, Nanjing Agricultural University, 210095 Nanjing, Jiang Su, China; and Department of Plant Sciences, University of Tennessee, Knoxville, TN 37996 Additional index words. nodal segments, proliferation, plant growth regulators, acclimatization,
rooting induction

\begin{abstract}
Pyracantha coccinea is a thorny evergreen shrub native to southeast Europe to southeast Asia. It is a popular ornamental plant because of its showy bright red fruits and small white flowers. However, in vitro vegetative propagation of $P$. coccinea has not been studied. Nodal segments with one or two axillary buds (1 to $1.5 \mathrm{~cm}$ in length) were cut and disinfected in a solution of $0.1 \%(\mathrm{v} / \mathrm{v})$ mercuric chloride $\left(\mathrm{HgCl}_{2}\right)$ for 5 minutes, and proliferated on Murashige and Skoog (MS) basal medium supplemented with various concentrations 6-benzylaminopurine (6-BA). After 4 weeks, newly formed shoots were transferred to proliferation and rooting media containing various concentrations of indole-3-butyric acid (IBA). Establishment of axillary buds was significantly better with an establishing rate of $67 \%$ on basal MS medium augmented with $6.6 \mu \mathrm{M}$ 6-BA. The best medium for proliferation of shoots was three-fourth basal MS supplemented with $1.5 \mu \mathrm{M}$ IBA, with a proliferation rate of 3.4 axillary bud. The optimum rooting medium was one-fourth MS basal medium containing $93 \mu \mathrm{M}$ IBA. Rooting of shoots was as much as $\mathbf{7 7 \%}$. Rooted plantlets were transferred to pots containing vermiculite:perlite:peat (6:1:2) and acclimatized to ambient greenhouse conditions with a $95 \%$ survival rate. This protocol can be used for in vitro propagation of $P$. coccinea.
\end{abstract}

Pyracantha coccinea M. Roem, also called scarlet firethorn, is a member of Rosaceae. It is an evergreen thorny perennial shrub and native to southeast Europe and Asia. It was introduced to North America in the 18th century and cultivated as an ornamental, medicinal, and nutritional plant (Fico et al., 2000; Potter et al., 2007). The plant is commonly used in commercial landscapes because of its abundant small, bright, showy red berries, open habit, and small, attractive white flowers. It is also often used as informal hedge or barrier plant, which is good for espaliers on walls and trellises. Scarlet firethorn berries are the most outstanding attribute of the species.

Flowering occurs in spring and the orange- to dark red-fleshy berries ripen in fall, which are usually eaten by birds. Ripe berries can be cooked to make jellies, jams, sauces, and marmalade (Quiroga et al., 2003). Pyracantha coccinea has great potential for further development not only for its ornamental value, but also for its food and

Received for publication 1 Sept. 2016. Accepted for publication 6 Dec. 2016.

This project was supported by the Jiangsu Agricultural Science and Technology Innovation Fund of China, project number CX (14) 2051, and in part by the Tennessee Agricultural Experiment Station, United States.

${ }^{1}$ Corresponding author. E-mail: zcheng@utk.edu. medicinal values. The fruits of scarlet firethorn are commonly used in traditional medicine for diuretic, cardiac, and tonic properties (Kowaleuki and Mrugasiewicz, 1971). Moreover, Keser (2014) found that the berries contained antiradical and phytochemical properties. Pyracantha coccinea berries also have a good potential for the biosorptive removal of basic dyes (Akar et al., 2009) and as a biomonitor species for some heavy metals including copper and nickel (Akguc et al., 2010).

Traditionally, scarlet firethorn has been propagated by seeds, which require stratification at $5{ }^{\circ} \mathrm{C}$ for $90 \mathrm{~d}$ (Olmez et al., 2007). Softwood cuttings have also been used to propagate the plant and rooting required treatment with 1000 to $3000 \mathrm{ppm}$ IBA and grown under mist (Dirr and Heuser, 2009). Currently, there is no in vitro micropropagation protocol using nodal cuttings for $P$. coccinea. The objective of this research was to develop an in vitro micropropagation protocol for $P$. coccinea.

\section{Materials and Methods}

Explants selection. One-year-old seedlings of $P$. coccinea, grown in a greenhouse at Nanjing Agricultural University, Nanjing, China, were used as donor plants. Young, soft shoots from healthy plants were harvested in Mar. 2014. Leaves were removed before the shoots were rinsed with tap water for $2 \mathrm{~h}$ and cut into 1 - to $1.5-\mathrm{cm}$ lengths with one or two nodes.

Microshoot establishment. Nodal segments were surface disinfected in $70 \%(\mathrm{v} / \mathrm{v})$ ethanol for $30 \mathrm{~s}$ and washed with sterile water for five times for $2 \mathrm{~min}$ each. Explants were soaked in $0.1 \%(\mathrm{v} / \mathrm{v}) \mathrm{HgCl}_{2}$ solution for $5 \mathrm{~min}$ and then rinsed with sterile water five times for $2 \mathrm{~min}$ each (Qu et al., 2000). Surface disinfected nodal segments were trimmed and transferred to $100-\mathrm{mL}$ Pyrex glass bottles containing $50 \mathrm{~mL}$ of MS (Murashige and Skoog, 1962) basic medium supplemented with $30 \mathrm{~g}$ sucrose and either $0,2.2$, 6.6 , or $11.0 \mu \mathrm{M} 6$-BA. The $\mathrm{pH}$ of the media was adjusted to $5.8 \pm 0.1$ with $1 \mathrm{~N} \mathrm{NaOH}$ or 1 $\mathrm{N} \mathrm{HCl}$ before adding phytagar $(8 \mathrm{~g} / \mathrm{L})$ and then autoclaved for $20 \mathrm{~min}$ at $121^{\circ} \mathrm{C}$ and $117.68 \mathrm{kPa}$. Thirty shoots were prepared for each treatment. In the first week, the microshoots were cultured in the dark with $24 \pm$ $2{ }^{\circ} \mathrm{C}$ and thereafter cultured at $24 \pm 2{ }^{\circ} \mathrm{C}$ with a photoperiod at $16 / 8 \mathrm{~h}$ light/dark with the light intensity of $100 \mu \mathrm{mol} \cdot \mathrm{m}^{-2} \cdot \mathrm{s}^{-1}$. After 30 $\mathrm{d}$, newly formed shoots were used for subsequent experiments.

Microshoot proliferation. Established microshoots of $P$. coccinea were dissected under a laminar hood and transferred into $100-\mathrm{mL}$ Pyrex glass bottles containing $50 \mathrm{~mL}$ of medium. The treatments were three-fourth MS basal medium-supplemented $30 \mathrm{~g}$ sucrose and either IBA at four levels $(0,1$, 1.5 , and $2.0 \mu \mathrm{M})$. Thirty cultures were prepared for each treatment. The number of proliferated microshoots was counted after 4 weeks.

Rooting induction. Microshoots, equal to or longer than $1.5 \mathrm{~cm}$ in length, were excised from cultures and used to study root induction. The treatments were one-fourth MS basal medium supplemented with either 0 , $83,88,93$, or $98 \mu \mathrm{M}$ IBA. All media contained $30 \mathrm{~g}$ of sucrose and $5.6 \mathrm{~g}$ of agar and the $\mathrm{pH}$ was adjusted to 5.8 before autoclaving. Thirty replications of one shoot were used for each treatment. Cultures were incubated at $24 \pm 2{ }^{\circ} \mathrm{C}$, with $16 / 8 \mathrm{~h} \mathrm{light/dark}$ (the light intensity is $100 \mu \mathrm{mol} \cdot \mathrm{m}^{-2} \cdot \mathrm{s}^{-1}$ ), and the relative humidity was $70 \% \pm 5 \%$. After culturing for 1 month, the number of rooted microcuttings and the number of roots per microcutting were determined.

Acclimatization and transplanting. The lids of the glass bottles in which the rooted cuttings grown to about $5.0 \mathrm{~cm}$ were partially opened after $2 \mathrm{~d}$ of partial opened lids, three or four drops of sterile water were added to each bottle. The lid was completely removed on the 4th $\mathrm{d}$. The plantlets were prepared for transplanting into pots and by carefully washing the agar from the roots with sterile water, and then transplanted into the $1.5-\mathrm{L}$ pots with sterile 6 vermiculite : 4 peat : 1 perlite growth medium. Transplanted plantlets were placed in a greenhouse and watered as needed. After 4 weeks, the number of surviving plants was recorded.

Statistical analysis. A completely randomized design was used in all experiments and experiments were repeated three times. 
All data were analyzed using one-way analysis of variance associated with Tukey's post hoc test at $\alpha \leq 0.05$. Statistical analysis was performed using IBM SPSS statistical software (v.19.0).

\section{Results}

Microshoot establishment. The initial disinfection procedure successful with one shoot was contaminated from 20 shoots treated; therefore, no further experiment was performed to compare different disinfection procedure. 6-BA greatly affected in vitro establishment of scarlet firethorn nodes (Table 1). Significantly more nodes were established using medium containing $6.6 \mu \mathrm{M} 6-\mathrm{BA}$ then other treatments containing 6-BA. There was no significant difference between the number of nodes established on control medium $(0 \mu \mathrm{M})$ and medium with $6.6 \mu \mathrm{M} 6$-BA. Vitrification of many microshoots occurred on medium augmented with $11 \mu \mathrm{M}$ 6-BA.

Microshoots proliferation. The concentration of IBA significantly influenced elongation of Scarlet Firethorn microshoots (Table 2). The highest number of microshoots was obtained on medium containing $1.5 \mu \mathrm{M}$ IBA. The lowest rate of proliferation was on medium supplemented with $2 \mu \mathrm{M}$ IBA, and was significantly lower than the rate of the control and the $1.0 \mu \mathrm{M}$ treatment.

Rooting induction. Microcuttings of $P$. coccinea could not be rooted on MS medium with or without auxin, one-half MS without auxin, and one-fourth MS at less than $74 \mu \mathrm{M}$ IBA (data not shown). One-half strength MS medium supplemented with various concentrations of IBA supported very little root formation on microshoots (data not shown). 2,4-D significantly enhanced rooting of $P$. coccinea microshoots. No roots formed on the control $(0)$ or $2.3 \mu \mathrm{M}$ 2,4-D. The addition of 4.6 and $6.9 \mu \mathrm{M}$ of $2,4-\mathrm{D}$ to the medium significantly increased the percentage of microshoots that rooted. The highest rooting percentage, $57 \%$, was obtained on the medium with $6.9 \mu \mathrm{M}$, which was significantly higher than from all other treatments. However, $9 \mu_{\mathrm{M}} 2,4-\mathrm{D}$ significantly decreased the rooting percentage. The number of the roots per microcutting had the similar trend as the rooting percentage (Table 3).

Microshoots of $P$. coccinea rooted in one-fourth MS medium supplemented with high concentrations of IBA (Table 4). Rooting percentage of microshoots significantly increased with increasing concentrations of IBA concentration, but significantly decreased at the concentration of $98 \mu \mathrm{M}$ IBA. The best medium for rooting of $P$. coccinea microcuttings was one-fourth MS containing $93 \mu \mathrm{M}$ IBA. Medium supplemented with 84,89 , or $93 \mu \mathrm{M}$ IBA-induced root formation and had the similar effect on the number of roots per microcutting, which was significantly higher than the concentration of IBA lower than either 74 or $98 \mu \mathrm{M}$ IBA

Table 1. Microshoot establishment of Pyracantha coccinea on medium ${ }^{z}$ containing 6-benzylaminopurine (6-BA).

\begin{tabular}{lccc}
\hline $6-\mathrm{BA}(\mu \mathrm{M})^{\mathrm{z}}$ & No. of explants & No. of new shoots & Establishing rate $(\%)^{\mathrm{y}}$ \\
\hline 0 & 30 & 20 & $66.7 \mathrm{a}$ \\
2.2 & 30 & 10 & $33.3 \mathrm{c}$ \\
6.6 & 30 & 20 & $66.7 \mathrm{a}$ \\
11 & 30 & 13 & $43.3 \mathrm{~b}$ \\
\hline
\end{tabular}

${ }^{\mathrm{z}}$ The basal medium was Murashige and Skoog (1962) medium.

${ }^{\mathrm{y}}$ Percentages followed by different letters are significantly different at $5 \%$ level; new shoot number $=$ the number of new axillary buds/the total number of axillary buds per treatment $\times 100$.

Table 2. The effect of various media ${ }^{z}$ on microshoots proliferation of Pyracantha coccinea.

\begin{tabular}{lccc}
\hline Indole-3-butyric acid $(\mu \mathrm{M})^{\mathrm{z}}$ & No. of explants & No. of proliferated microshoots & Proliferation index \\
\hline 0 & 30 & 90 & $3.0 \mathrm{~b}$ \\
1 & 30 & 90 & $3.0 \mathrm{~b}$ \\
1.5 & 30 & 102 & $3.4 \mathrm{a}$ \\
2.0 & 30 & 60 & $2.0 \mathrm{c}$ \\
\hline
\end{tabular}

${ }^{\mathrm{z}}$ The basal medium was three-fourth Murashige and Skoog (1962) medium.

${ }^{\mathrm{y}}$ Different letters indicate analysis of variance was $5 \%$ significance level; new shoot number $=$ the number of new axillary buds/the total number of axillary buds per treatment $\times 100$.

Table 3. The effect of 2,4-D on microshoot root formation of Pyracantha coccinea after 3 months.

\begin{tabular}{lcccc}
\hline $2,4-\mathrm{D}$ concn $(\mu \mathrm{M})^{\mathrm{z}}$ & No. of explants & No. of rooted microcuttings & ${\text { Rooting rates }(\%)^{\mathrm{y}}}^{\text {No. of roots }}$ \\
\hline 0 & 30 & 0 & $0 \mathrm{~d}$ & $0 \mathrm{c}$ \\
2.3 & 30 & 0 & $0 \mathrm{~d}$ & $0 \mathrm{c}$ \\
4.5 & 30 & 3 & $10 \mathrm{c}$ & $2.3 \mathrm{~b}$ \\
6.8 & 30 & 17 & $56.7 \mathrm{a}$ & $6.5 \mathrm{a}$ \\
9.0 & 30 & 7 & $23.3 \mathrm{~b}$ & $3.6 \mathrm{~b}$ \\
\hline
\end{tabular}

${ }^{\mathrm{z}}$ The basal medium was one-half Murashige and Skoog (1962) medium.

${ }^{\mathrm{y}}$ Different letters indicate analysis of variance was $5 \%$ significance level; rooting rate $=$ the number of rooted microshoots/total number of microshoots per treatment.

Table 4. The effect of indole-3-butyric acid (IBA) on adventitious root formation of Pyracantha coccinea after 6 weeks.

\begin{tabular}{lcccc}
\hline IBA $(\mu \mathrm{M})^{\mathrm{z}}$ & No. of explants & No. of rooted microcuttings & ${\text { Rooting rates }(\%)^{\mathrm{y}}}$ & No. of roots \\
\hline $0-74$ & 30 & 0 & $0 \mathrm{e}$ & $0 \mathrm{c}$ \\
84 & 30 & 10 & $33.3 \mathrm{c}$ & $5.6 \mathrm{a}$ \\
89 & 30 & 19 & $63.3 \mathrm{~b}$ & $6.4 \mathrm{a}$ \\
93 & 30 & 23 & $76.7 \mathrm{a}$ & $6.4 \mathrm{a}$ \\
98 & 30 & 4 & $13.3 \mathrm{~d}$ & $3.5 \mathrm{~b}$ \\
\hline
\end{tabular}

${ }^{\mathrm{z}}$ The basal medium was one-half Murashige and Skoog (1962) medium.

${ }^{\mathrm{y}}$ Different letters indicate analysis of variance was $5 \%$ significance level; rooting rate $=$ the number of rooted microshoots/total number of microshoots per treatment.

(Table 4). However, they had different effect on the rooting percentage of $P$. coccinea. Medium supplemented with 0 to $107 \mu \mathrm{M}$ NAA was also tested, but did not induce rooting (data not shown).

Acclimatization and transplanting. Ninetyfive percent of the plantlets survived transplantation and acclimation to greenhouse environmental conditions (Fig. 1).

\section{Discussion}

Many woody ornamental plants are very recalcitrant to vegetative propagation by conventional cutting methods. Therefore, in vitro propagation method has been developed, but each species may require a very different protocol with different challenges. The possible reasons for difficulty for in vitro propagation include high contamination rate at the initial stage, the physiological status of the explants, and/or their slow growing characteristics (Chen, 1995; Tan and Dia, 1991).
Bud dormancy of the explant is one of the most important limitations for propagating woody species, which usually overcome by using cytokinin to break dormancy. However, the improper concentration of cytokinin often causes vitrification of the explant (Hanover and Keathley, 1988). In this research for $P$. coccinea, we used $6.6 \mu \mathrm{M} 6$-BA to initiate shoot growth and proliferation, and this concentration has been reported as suitable for the microshoot establishment of many species, including Siberian elm (Ulmus pumila) (Cheng and Shi, 1995). Shoot proliferation of $P$. coccinea was affected by the concentration of auxin and the nutrient salt content of media. We found that decrease of the macronutrient content in the culture medium increased the shoot proliferation rate. In this stage, the shoots proliferated without adding any exogenous cytokinin, and was probably due to the high endogenous cytokinins in microshoots or the retention of exogenous 6-BA in the medium used in the 

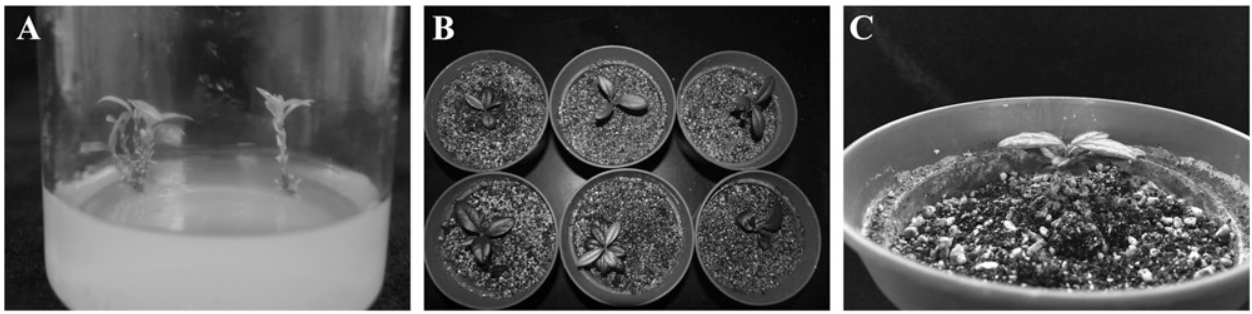

Fig. 1. Micropropagation of Pyracantha coccinea. (A) Elongated and proliferating shoots; (B) transplanted plantlets; and (C) acclimatized plantlet.

establishment stage (Kevers et al., 1984). Further research is needed on the shoot proliferation stage of $P$. coccinea.

Root formation of $P$. coccinea was significantly affected by the auxin types and concentration, and the macronutrients contained in the media. The results in this study indicated that the lower content of macronutrients in the culture medium improved shoot proliferation. One significant difference in this study from many other micropropagation studies was the use of 2,4-D as the auxin for rooting, which was rarely reported in micropropagation (Thakur and Kanwar, 2008). Another striking difference is the use of extremely high concentration of IBA, which significantly increased the rooting percentage from $0 \%$ to $77 \%$ in 1.5 months. Although the extremely high concentration of IBA reported here for root induction is not commonly used, it had been reported for rooting initiation in redbud (Cercis canadensis) (Dai et al., 2005). The high auxin concentration needed for inducing roots, is probably because the scarlet firethorn is a woody plant, which are normally difficult to root (Dirr and Heuser, 2009). This may also explain why 2,4-D could induce roots as it is a strong synthetic auxin. Once rooted, the plantlets can be transferred and acclimated to ambient environment. This micropropagation protocol allows to potentially massive production of elite germplasm or newly released cultivars of $P$. coccinea.

\section{Literature Cited}

Akar, T., B. Anilan, A. Gorgulu, and S.T. Akar. 2009. Assessment of cationic dye biosorption characteristics of untreated and non-conventional biomass: Pyracantha coccinea berries. J. Hazard. Mater. 168:1302-1309.

Akguc, N., I.I. Ozyigit, U. Yasar, Z. Leblebici, and C. Yarci. 2010. Use of Pyracantha coccinea Roem as a possible biomonitor for the selected heavy metals. Intl. J. Environ. Sci. Technol. 7(3): 427-434.

Chen, Z. 1995. In vitro culture of horticultural plants. Chinese Agriculture Press, Beijing, China.

Cheng, Z.-M. and N.-Q. Shi. 1995. Micropropagation of mature Siberian elm in two steps. Plant Cell Tiss. Org. Cult. 41:197-199.

Dai, W., V. Jacques, D. Herman, and Z.-M. Cheng. 2005. Micropropagation of a cold hardy selection of Cerciscanadensis L. through singlenode culture. J. Environ. Hort. 23:54-58.

Dirr, M.A. and J.C.W. Heuser. 2009. Reference Manual of Woody Plant Propagation.

Fico, G.R., A. Bilia, I. Morelli, and F. Tomè. 2000 Flavonoid distribution in Pyracantha coccinea plants at different growth phases. Biochem. Syst. Ecol. 28:673-678.

Hanover, J.W. and D.E. Keathley. 1988. Genetic manipulation of woody plants. Bioscience 44 (39):139-149.
Keser, S. 2014. Antiradical activities and phytochemical compounds of firethorn (Pyracantha coccinea) fruit extracts. Nat. Prod. Res. 28(20): 1789-1794.

Kevers, C., M. Coumans, M.F. Coumans-Gillès, and T. Caspar. 1984. Physiological and biochemical events leading to vitrification of plants cultured in vitro. Physiol. Plant. 61(1): 69-74.

Kowaleuki, Z. and M. Mrugasiewicz. 1971. Neue flavanonheteroside in Crataegus phenophyrum. Planta Med. 19:311-313.

Olmez, Z., F. Temel, A. Gokturk, and Z. Yahyaoglu. 2007. Effect of cold stratification treatments on germination of drought tolerant shrubs seeds. J. Environ. Biol. 28(2):447-453.

Potter, D., T. Eriksson, R.C. Evans, S. Oh, J.E.E. Smedmark, and D.R. Morgan. 2007. Phylogeny and classification of rosaceae. Plant Syst. Evol. 266(1):5-43.

Qu, L., J. Polashock, and N. Vorsa. 2000. A highly efficient in vitro cranberry regeneration system using leaf explants. HortScience 35:948952.

Quiroga, O.E., S.M. Bou, C.I. Sarlingo, and S.M. Nolasco. 2003. Study of the composition of Pyracantha crenulata roem seed, oil and meal. Grasas Aceites 54(4):335-338.

Tan, W. and C. Dai. 1991. Technology of tissue culture of ornamental plant. Chinese Forestry Press, Beijing, China.

Thakur, A. and J.S. Kanwar. 2008. Micropropagation of 'wild pear' Pyrus pyrifolia (Burm F.) Nakai. II. Induction of rooting. Not. Bot. Hort. Agrobot. Cluj-Napoca 36(2):104-111. 